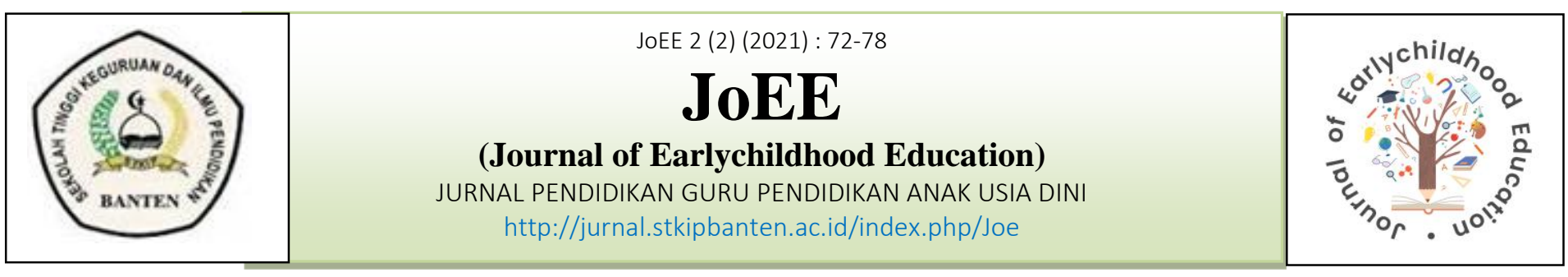

\title{
STUDI LITERATUR PENGARUH FINGER PAINTING TERHADAP PERKEMBANGAN SENI LUKIS ANAK USIA DINI
}

\author{
Larasati Nur Indah Prawesti ${ }^{1}$, Heni Herlina ${ }^{2}$, dan Yeyen Tahani ${ }^{3}$ \\ ${ }^{1}$ Sekolah Tinggi Keguruan dan Ilmu Pendidikan Banten \\ ${ }^{2}$ Sekolah Tinggi Keguruan dan Ilmu Pendidikan Banten \\ ${ }^{3}$ Mahasiswa Pendidikan Guru Pendidikan Anak Usia Dini \\ Penulis Korespondensi:, $\underline{\text { iiazzprawesti@gmail.com }}{ }^{1}$, heniherlina.ss.mpd@gmail.com², \\ yeyentahani81@gmail.com ${ }^{3}$ \\ Penerima: Juli 2021 \\ Artikel: Perkembangan Seni Lukis Anak Usia Dini \\ Diterima: Agustus 2021 Dipublikasikan: September 2021
}

\begin{abstract}
Finger painting is a type of drawing activity that is carried out by scratching the color mixture (color pulp) directly with the fingers freely in the drawing field, the limits of the fingers here are all fingers, palms, to wrists. In this study finger painting is very influential to improve early childhood painting. The purpose of this study is to find out how the influence of finger painting on the improvement of early childhood painting. This research is a literature study. In accordance with the object of this thesis study, this type of research is included in the category of library research. Where the data collection system in this study is sourced from journals which are analyzed based on existing problems. Literature study is an activity related to the method of collecting library data, reading, taking notes, and processing research materials. So it can be concluded that Finger Painting is very influential in early childhood painting.
\end{abstract}

Keywords: finger painting, early childhood painting

\begin{abstract}
ABSTRAK
Finger painting adalah jenis kegiatan membuat gambar yang dilakukan dengan cara menggoreskan adonan warna (bubur warna) secara langsung dengan jari tangan secara bebas di bidang gambar, batasan jari disini adalah semua jari tangan, telapak tangan, sampai pergelangan tangan. Dalam penelitian ini finger painting sangat berpengaruh untuk meningkatkan seni lukis Anak Usia Dini. Tujuan penelitian ini ialah Untuk mengetahui bagaimana pengaruh finger painting terhadap peningkatan seni lukis anak usia dini, Penelitian ini merupakan penelitian studi literatur. Sesuai dengan obyek kajian skripsi ini, maka jenis penelitian ini termasuk dalam kategori penelitian kepustakaan (library research). Dimana sistem pengambilan data dalam penelitian ini bersumber dari Jurnal-jurnal yang dianalisis berdasarkan permasalahan yang ada. Studi literatur merupakan kegiatan yang berkenaan dengan metode pengumpulan data pustaka, membaca, mencatat, serta mengolah bahan penelitian. Sehingga dapat di simpulkan bahwa Finger Painting sangat berpengaruh dalam seni lukis anak usia dini.
\end{abstract}

Kata Kunci: finger painting, Seni Lukis anak usia dini (C) 2021, JoEE, Jurnal of Early Childhood. PGPAUD e-ISSN: 2775-7870 


\section{PENDAHULUAN}

Pendidikan sangatlah penting diberikan sejak dini. Sebab pendidikan merupakan salah satu upaya yang dapat dilakukan untuk memajukan budi pekerti, pikiran serta jasmani anak, agar membentuk karakter anak yang selaras dengan lingkungan dan masyarakat. Konsep dasar pendidikan anak usia dini (PAUD) adalah pendidikan untuk anak prasekolah yang diselenggarakan untuk membantu pertumbuhan dan perkembangan anak secara keseluruan sebagai bekal anak memasuki tahap kehidupan selanjutnya. Pendidikan anak usia dini bermanfaat sebagai penyedia fasilitas untuk menstimulasi pertumbuhan dan perkembangan anak secara menyeluruh sehingga melatih anak untuk berkreasi ( Okda \& Astuty, 2017). Permainan yang dapat diterapkan pada kegiatan pembelajaran di TK salah satunya dengan bermain finger painting Melalui kegiatan ini, anak akan dibebaskan beresplorasi dan berekperimen sehingga anak lebih memaknai pembelajaran. Hasil penelitian terdahulu oleh Astria (2014) menyatakan bahwa kegiatan finger painting adalah cara menyampaikan kegiatan pembelajaran yang tepat kepada anak pada saat berlangsungnya proses pembelajaran sehingga menghasilkan pemahaman yang maksimal.

Pada saat bermain finger painting, anak diberikan kebebasan untuk berekspresi dan bereksplorasi dengan media sehingga kreativitas anak akan berkembang. Hal ini didukung dengan hasil penelitian yang terdahulu oleh Istiana (2014) yang menyatakan finger painting digunakan anak untuk meningkatkan kreativitas melalui jari tangan, dengan adanya gerakan jari tangan, anak bebas mengekspresikan dirinya.
Seringkali kegiatan pembelajaran yang dilakukan di TK dilakukan didalam kelas sehingga kegiatan pembelajaran tidak begitu kondusif. Selama penelitian, penulis akan melakukan kegiatan pembelajaran di luar kelas sehingga kegiatan kreativitas melukis anak dapat meningkat sesuai dengan harapan. Berdasarkan hasil wawancara penulis dengan salah satu guru TK, disana memang sering adanya kegiatan melukis,namun kegiatan yang dilakukan belum efektif. Biasanya guru mengajarkan keterampilan melukis itu cenderung memberi perintah dengan mengikuti instruksi guru, dengan metode seperti ini maka akan menjadikan imajinasi anak tidak berkembang dengan baik.

Misalnya, mewarnai gambar daun, guru memberi instruksi bahwa daun itu berwarna hijau, sedangkan dunia imajinasi anak itu sangat luas, anak dapat memberikan warna daun sesuai dengan ide baru mereka. Dengan memberi kebebasan berkreasi, anak mampu meningkatkan kreativitasnya dalam melukis. Dari beberapa permasalahan tersebut, penulis mengajukan salah satu metode pembelajaran yang sesuai untuk meningkatkan kreativitas melukis anak. Adapun metode yang digunakan oleh penulis adalah metode Finger Painting. Menurut Montolalu pembelajaran melukis menggunakan jari atau finger painting memiliki tujuan yaitu mengekspresikan kesenangannya melalui media lukis dengan menggunakan bagian telapak tangan dan jari jemari tangan untuk melatih otot-otot tangan dan jari, koordinasi mata tangan, melati kecakapan mengkombinasikan warna, memupuk perasaan terhadap gerakan tangan. 


\section{KAJIAN TEORI}

Finger painting adalah jenis kegiatan membuat gambar yang dilakukan dengan cara menggoreskan adonan warna (bubur warna) secara langsung dengan jari tangan secara bebas di bidang gambar, batasan jari disini adalah semua jari tangan, telapak tangan, sampai pergelangan tangan.

Seni lukis adalah bahasa ungkapan dari pengalaman artistik maupun ideologis yang menggunakan warna dan garis, guna mengungkapkan perasaan,

mengekpresikan emosi gerak, ilusi maupun ilustrasi dari kondisi subjektif seseorang. Menurut Bahari (2008:67) seni lukis adalah karya seni rupa dua dimensional yang menampilkan unsur warna, bidang garis, bentuk, dan tekstur.

Menurut Bangun (2005:6) seni lukis merupakan penggunaan garis, warna, tekstur, ruang dan bentuk, shape, pada suatu permukaan yang bertujuan untuk menciptakan berbagai image. Image-image tersebut bisa merupakan pengekspresian ide-ide, emosi, dan pengalamanpengalaman yang dibentuk sedemikian rupa sehingga mencapai harmoni.

\section{METODE}

Penelitian ini merupakan penelitian studi literatur. Sesuai dengan obyek kajian skripsi ini, maka jenis penelitian ini termasuk dalam kategori penelitian kepustakaan (library research). Dimana sistem pengambilan data dalam penelitian ini bersumber dari Jurnal-jurnal yang dianalisis berdasarkan permasalahan yang ada. Studi literatur merupakan kegiatan yang berkenaan dengan metode pengumpulan data pustaka, membaca, mencatat, serta mengolah bahan penelitian.

\section{HASIL DAN PEMBAHASAN Hasil}

Setelah data di Analisis terhadap 10 jurnal yaitu 6 jurnal nasional dan 4 jurnal internasional hasil penelitian yang secara

(C) 2021, JoEE, Jurnal of Early Childhood. PGPAUD e-ISSN: 2775-7870 garis besar terdapat beberapa 5 jurnal hasil temuan literature yang direview pada penelitian ini antara lain sebagai berikut:

1. Penelitian dari Lenni Marlina dan Farida Mayar (2020) Penelitian ini berawal dari kurang berkembangnya kreativitas anak - anak di Taman Kanak- kanak ( TK ) Bhayangkari 01 Padang. Sehingga dibutuhkan suatu kegiatan kreatif yang menarik minat anak untuk merangsang perkembangan kreativitas anak sesuai kebutuhan anak. Penelitian ini dilakukan untuk melihat pelaksanaan kegiatan finger painting dalam mengembangkan kreativitas seni anak di TK. Metode penelitian yang digunakan adalah studi literatur. Teknik pengumpulan data dengan menelaah sumber sekunder berupa buku referensi dan jurnal yang relevan dengan masalah penelitian.

2. Penelitia dari Sri Rahayu Hader, Bahran Taib, Santi M.J.Wahid (2017) Kreativitas sangat penting untuk dikembangkan bagi anak usia dini karena akan menciptakan pengalaman-pengalaman yang bisa menumbuhkan percaya diri dan sikap positif untuk perkembangan anak secara optimal. Adapun salah satu finger painting yang dapat mengembangkan kemampuan kreativitas anak yaitu melalui kegiatan finger painting, dengan kegiatan finger painting merupakan salah satu kegiatan untuk mengembangkan kreativitas anak. Metode penelitian yang digunakan dalam penelitian ini dengan pendekatan studi (library research). Adapun salah satu kegiatan yang dapat diterapkan dalam mengembangkan kreativitas anak yaitu dengan menggunakan finger painting. Dapat disimpulkan bahwa ada pengaruh teknik melukis (finger painting) terhadap kreativitas anak.

3. Penelitian dari Maria Evivani dan Renti Oktavia (2020) bertujuan untuk dapat mengetahui seberapa penting penerapan yang dilakukan melalui permainan finger painting dalam pengembangan 
kemampuan motorik halus anak yang menggunakan jari-jemari tangan dan gerakan pergelangan tangan yang sesuai dengan Standar Pencapaian Perkembangan Anak (STPPA) yang termuat di dalam Peraturan Menteri pendidikan dan Kebudayaan (PERMENDIKBUD) Nomor 137 Tahun 2014 Tentang Standar Nasional Pendidikan Anak usia Dini. Kemampuan motorik halus pada permainan ini akan melibatkan perkembangan otot-otot kecil khususnya pada bagian tangan anak. Maka dari itu penerapan permainan finger painting ini diharapkan dapat sesuai dalam pencapaian perkembangan motorik halus anak dan permainan ini tidak menyimpang dari hakikat anak yaitu belajar melalui bermain yang secara tidak langsung akan mengembangan motorik halus anak yang tertuang dalam STPPA terkait gerakan tangan yaitu mengkoordinasikan tangan dan mata untuk melakukan gerakan rumit, melakukan gerakan manipulatif untuk menghasilkan suatu bentuk dengan berbagai media, dan mengekspresikan diri dengan berkarya seni menggunakan berbagai media. Pendekatan yang digunakan menggunakan metode deskriptif melalui kajian pustaka yang ada disekitar.

4. Penelitian dari Septia Anggraini, M.Thoha B.S Jaya, Ari Sofia Pengaruh aktivitas permainan finger painting terhadap pengenalan warna anak kelompok b usia 5-6 tahun di TK Bela Bangsa Mandiri Bandar Lampung. Masalah pada penelitian ini adalah belum berkembangnya pengenalan warna pada anak usia 5-6 tahun. Penelitian ini bertujuan untuk mengetahuipengaruh aktivitas permainan finger painting pada anak usia 5-6 tahun. Jenis penelitian ini merupakan penelitian kuantitatif yang bersifat pre- experimental dengan desain kuantitatif. Sampel penelitian menggunakan multistage random sampling sebanyak 30 anak kelas eksperimen dan 27 anak kelas kontrol. Teknik pengumpulan data yang digunakan yaitu observasi dan dokumentasi. Sedangkan analisis data yang digunakan yaitu paired sample $t$ test dan analisis regresi linear sederhana. Hasil penelitian menunjukkan bahwa ada perbedaaan pengenalan warna antara anak yang belajar menggunakan permainan finger painting dengan anak yang belajar tanpa menggunakan permainan finger painting dan ada pengaruh aktivitas permainan finger painting terhadap pengenalan warna pada anak kelompok B usia 5-6 tahun di TK Bela Bangsa Mandiri Bandar Lampung.

5. Penelitian dari Selia Dwi Kurnia (2015) Penelitian ini bertujuan untuk mengetahui pengaruh kegiatan painting dan keterampilan motorik halus terhadap kreativitas anak usia dini dalam seni lukis kelompok B taman kanak-kanak. Metode penelitian ini menggunakan penelitian eksperimen dengan desain treatment by level $2 \times 2$. Sampel dalam penelitian ini sebanyak 66 anak. Teknik pengumpulan sampel teknik multistage sampling. Teknik analisis data menggunakan ANAVA dua jalur. Hasil penelitian yang diperoleh adalah: 1) hasil kreativitas anak usia dinidalam seni lukis pada kelompok anak yang diberi kegiatan finger painting lebih tinggi dibandingkan kelompok anak yang diberi kegiatan brush painting, 2) terdapat pengaruh interaksi antara kegiatan painting dan keterampilan motorik halus terhadap kreativitas anak usia dini dalam seni lukis, 3) hasil kreativitas anak usia dini dalam seni lukis pada kelompok anak yang memiliki keterampilan motorik halus tinggiyang diberi kegiatan finger painting lebih tinggi dibandingkan 
kelompok anak yang diberi kegiatan brush painting, 4) hasil kreativitas anak usia dini dalam seni lukis pada kelompok anak yang memiliki keterampilan motorik halus rendah yang diberi kegiatan finger painting lebih rendah dibandingkan kelompok anak yang diberi kegiatan brush painting.

\section{Pembahasan}

Berdasarkan penelitian dan hasil analisis data yang telah dilakukan, maka dapat di bahas bahwa Pembahasan teori

a. Bermain finger painting adalah jenis kegiatan membuat gambar yang dilakukan dengan cara menggoreskan adonan warna (bubur warna) secara langsung dengan jari tangan secara bebas diatas bidang gambar, batasan jari disini adalah semua jari tangan, telapak tangan.

b.Kemampuan seni lukis anak adalah salah satu keindahan yang ditimbulkan oleh pantulan cahaya yang mengenai permukaan suatu benda/ dalam suatu cahaya yang sempurna (berwarna putih) kemudian warna juga berwujud garis bidang, ruang, nada, gelap, terang, bentuk nilai dan ukuran.

c. Bermain finger painting berpengaruh terhadap peningkatan seni lukis, karena dalam finger painting warna-warna yang digunakan lebih jelas. Dengan kegiatan ini pula, anak lebih mudah memahami pengetahuan warna, sehingga kemampuan anak dalam pengetahuan warna dapat berkembang lebih optimal dan anak tidak akan mengalami kesulitan lagi dalam menyebutkan warna-warna baru yang dihasilkan dari proses pencampuran warna.

\section{KESIMPULAN DAN SARAN}

\section{Kesimpulan}

Berdasarkan penelitian dan hasil analisis data yang telah dilakukan, maka dapat disimpulkan bahwa: Finger painting dapat mengembangkan seni lukis anak usia dini dengan mandiri, penuh imajinasi dan mengahsah bakat.

(C) 2021, JoEE, Jurnal of Early Childhood. PGPAUD e-ISSN: 2775-7870

\section{Saran}

Berdasarkan penelitian yang sudah dilakukan, maka diperlukan saran-saran antara lain sebagai berikut:

1. Untuk pihak sekolah dapat menjadikan kegiatan seni finger painting sebagai kegiatan alternatif untuk meningkatkan serta mengoptimalkan seni lukis anak usia dini, serta mampu memberikan atau menyediakan fasilitas finger painting.

2. Untuk guru hendaknya dapat mengaplikasikan pembelajaran menggunakan kegiatan finger painting yang bertujuan untuk melatih kemampuan seni lukis pada anak usia dini. Dengan diberikannya kegiatan seni finger painting, anak usia dini dilatih untuk dapat dijadikan sebagai pengalaman baru bagi anak usia dini.

3. Untuk para peniliti lebih lanjut diharapkan untuk dapat mengkaji lebih jauh lagi mengenai kegiatan seni finger painting agar tidak hanya memberikan pengaruh pada kemampuan seni lukis nya saja, tetapi juga dapat meningkatkan kognitif maupun interaksi sosial pada anak usia dini.

\section{DAFTAR PUSTAKA}

Ramdini, Tiara Prima. 2019. Peranan Kegiatan Finger Painting Terhadap Perkembangan Seni Anak Usia Dini. Jurnal Pendidikan tambusai. Volume 3 Nomor 6.

Mayar, Farida., Sari, Dewi Nilam \& Hijriani, Aini. 2019. Analisa Manfaat Seni Untuk Mengoptimalkan Perkembangan Anak Usia Dini. Jurnal Pendidikan tambusai Volume 3 Nomor 6 Tahun 2019. ISSN 2614-6754 (Online)

Maulana, Ihsan. 2019. Pengembangan Kreativitas Anak Usia Dini Di Era Revolusi 4.0 Jurnal Pendidikan Tambusai. Volume 3 Nomor 5.

PGPAUD JURNAL 
Larasati Nur Indah Prawesti, Heni Herlina, dan Yeyen Tahani. Studi Literatur Pengaruh Finger Painting Terhadap Peningkatan Seni Lukis Anak Usia Dini

Amrullah, Silmi, Dkk. 2018. Studi Sistematik Aspek Kreativitas Dalam Konteks Pendidikan. Jurnal Ilmiah Psikologi Volume 5, Nomor 2, 2018: 187-200. eISSN 2502-2903, pISSN: 2356-3591. DOI: $10.15575 /$ psy.v5i2.3533

Nurhafizah. 2018. Pelatihan Pembuatan Media pembelajaran Anak Usia Dini Menggunakan Bahan Sisa. Jurnal Pendidikan Early Childhood Vol.2 No.2b

Mayar, Farida., Sari, Dewi Nilam \& Hijriani, Aini. 2019. Analisa Manfaat Seni Untuk Mengoptimalkan Perkembangan Anak Usia Dini. Jurnal Pendidikan tambusai Volume 3 Nomor 6 Tahun 2019. ISSN 2614-6754 (Online)

Rustandi, Tantan. 2010. Pintar Melukis Dengan Cat Akrilik. Jakarta: Wahyu Media.

Cahyati, Anis. 2015. Penerapan Metode Pemberian Tugas Melalui Kegiatan Finger Painting Untuk Meningkatkan Kreativitas. e-Journal PGPAUD Universitas Pendidikan Ganesha Volume 3 Nomor 1.

Montolalu dalam Maria Evivani, 2004. Permainan finger painting Untuk Pengembangan Kemampuan Motorik Halus Anak Usia Dini. Jurnal Pendidikan dan Pembelajaran Anak Usia Dini Maret 2020.Vol 05 No 01 (Diakses 29 Juni 2020)

Montalalu, 2009. Bermain dan Permainan. Jakarta: Universitas Terbuka

Kurniati, dkk, 2010.Strategi pengembangan kreativitas pada anak. Jakarta: Kecana Prenada Media Group 